\title{
Parental unemployment and youth life satisfaction: the moderating roles of
}

\section{satisfaction with family life}

Diana Frasquilho*1'; Margarida Gaspar de $\mathrm{Matos}^{2}$; Fergus Neville ${ }^{3}$; Tânia Gaspar ${ }^{4}$; JM Caldas de Almeida ${ }^{5}$

1* Nova Medical School and CMDT/IHMT, Nova University Lisbon, Portugal (diana.frasquilho@hbsc.org)

${ }^{2}$ Faculty of Human Kinetics and ISAMB, University of Lisbon; WJCR/ISPA, Portugal (mmatos@ fmh.ulisboa.pt)

${ }^{3}$ School of Medicine, University of St Andrews, St Andrews, Scotland, United Kingdom (fgn@st-and.ac.uk)

${ }^{4}$ Lisbon Lusíada University; ISAMB, University of Lisbon, Portugal. (tania.gaspar@edu.ulusiada.pt)

${ }^{5}$ Department of Mental Health, Nova Medical School, Nova University Lisbon, Portugal (caldasjm@fcm.unl.pt)

Corresponding author: Diana Frasquilho, Aventura Social, Faculdade de Motricidade Humana da Universidade de Lisboa, Estrada da Costa 1495-688 Cruz-Quebrada, Portugal. Email: diana.frasquilho@hbsc.org

Funding: Frasquilho D. receives a grant from the Portuguese Foundation for Science and Technology (FCT), reference SFRH / BD / 80846 / 2011

Conflict of Interest: The authors declare that they have no conflicts of interest. 


\begin{abstract}
While Europe is slowly recovering from the economic recession, its effects on labour markets are still visible. The number of jobless families has increased and previous research has shown that unemployment can affect the well-being of both parents and their children. This study develops our understanding of the links between parental unemployment and youth life satisfaction by considering the potential moderating roles played by satisfaction with family life and perceived family wealth.

Descriptive statistics, correlations, simple moderation and moderated moderation models of regression were performed on data from a representative sample of 3937 Portuguese students ( $M_{\text {age }}=13.9$ years $\pm 1.7 ; 47.8 \%$ boys $)$.

Results showed that the negative effects of parental unemployment on youth life satisfaction were moderated by youth perceived satisfaction with family life but not by perceived wealth. This study provides evidence that during family unemployment, young people satisfied with their family life are less vulnerable to the negative effects of parental unemployment on their life satisfaction. The relationship between parental unemployment and youth well-being requires further research, especially during periods of labour market crisis.
\end{abstract}

Keywords: adolescence, life-satisfaction, parental unemployment, family 


\section{Parental unemployment and youth life satisfaction: the moderating roles of}

\section{satisfaction with family life}

Unemployment is a major risk factor for psychological distress among adults (Paul \& Moser, 2009). Furthermore, there is evidence that unemployment in the family may follow an intergenerational course which can affect the well-being of both parents and their children (Baxter, Gray, Hand, \& Hayes, 2012).

Studying the possible effects of unemployment in the family on youth well-being is pertinent because the economic recession has increased unemployment rates and therefore the number of young people living in unemployed households in Euro area (from 7.6\% before the crisis 2007 to $10.5 \%$ in 2013) (Eurostat) and also because adolescence is an important developmental period susceptible to influences in the family environment that can ultimately modify youth developmental trajectories (Viner et al., 2012).

There is growing support for the claim that young people living in jobless families have poorer mental well-being, and decreased cognitive and social-emotional outcomes in comparison to those living in working families (Baxter et al., 2012; Siponen, Ahonen, Savolainen, \& Hameen-Anttila, 2011; Sleskova et al., 2006; Varga, Piko, \& Fitzpatrick, 2014). Along similar lines, the family stress model (R. D. Conger \& Donnellan, 2007) argues that young people's well-being deteriorates following parental job loss due to heightened parental distress levels and strain in family relations caused by economic hardship and pressure. Unemployed families experience more financial deprivation than working families (Fanjul, 2014; McClelland, 2000; Wall et al., 2013) and unemployed parents who become distressed may be short-tempered and less nurturing with their children (Christoffersen, 2000). Several studies have found that financial deprivation is associated with harsher parentadolescent relationships (Baxter et al., 2012; Broman, Hamilton, \& Hoffman, 1997; R.D. Conger \& Conger, 1992; Leinonen, Solantaus, \& Punamäki, 2002; Reising et al., 2013). 
Young people living in jobless families may therefore be affected by changes in daily family life which may increase vulnerability to low well-being. However, some studies have found that good family interactions may buffer the possible negative consequences of parental unemployment on youth well-being (Maria Bacikova-Sleskova, Madarasova Geckova, van Dijk, Groothoff, \& Reijneveld, 2011; Cui \& Conger, 2008; Willemen, Schuengel, \& Koot, 2011).

This study examined during a period of unemployment in a nationally representative sample of school-aged children, first if parental unemployment is associated with young people's low life satisfaction scores, and second if youth perceived family life satisfaction and financial deprivation may moderate such a relationship. Parental unemployment is expected to be negatively associated with young people's life satisfaction, and perceiving a positive family life is expected to moderate this association. Furthermore, perceived family wealth may interact with this interaction by moderating the moderation effect of family life satisfaction.

\section{Methods}

\section{Participants and procedures}

The analyses were based on data from the Health Behaviour in School-aged Children survey (HBSC/WHO) conducted in 2014. The HBSC study is carried out internationally every 4 years in 44 European and North American countries, in collaboration with the World Health Organisation. For this study we included a representative sample of 3937 Portuguese students from $8^{\text {th }}$ grade to $10^{\text {th }}$ grade $\left(M_{\text {age }}=13.9\right.$ years $\pm 1.7 ; 47.8 \%$ boys $)$.

According to the HBSC/WHO international standardized research protocol, the participants were recruited via a clustered sampling design (whole classes were used as sampling units) to meet the required number of students for each school grade from selected 
national schools (Currie et al. 2001; Roberts et al. 2009). All participant schools gave their approval and students' legal guardians gave signed informed consent. Students' participation was voluntary and the survey was self-completed after being sent to schools and administered in the classroom by teachers. Confidentiality was ensured as questionnaire responses were anonymous.

Ethics approval for the 2014 Portuguese HBSC was given from the Portuguese Ministry of Education and Health, by the ethics committee of São João Hospital, and by the national ethics committee.

\section{Measures}

Parental employment status was dichotomised into two groups: 1) both parents employed; 2) at least one parent unemployed (both parents were unemployed and looking for a job; only the father was unemployed and looking for a job; only the mother was unemployed and looking for a job).

Life satisfaction was measured by an adapted version of the Cantril Ladder (Cantril, 1965) on which adolescents rated their current life satisfaction as a measure of subjective wellbeing (Diener, Suh, Lucas, \& Smith, 1999). They were asked to indicate on a picture of a ladder where they felt they stood at the time (the top of the ladder 10 was the best possible life and the bottom 0 was the worst possible life). This scale has been validated and used in several studies to assess associations between several variables and mental and physical health in adolescents (C. Currie et al., 2008; R. L. Currie, 2009; Kuntsche \& Gmel, 2004; Molcho, Gabhainn, Kelly, Friel, \& Kelleher, 2007; Muldoon, Levin, van der Sluijs, \& Currie, 2010).

Satisfaction with family environment was evaluated with a Cantril's self-anchoring ladder (Cantril, 1965). Individuals were asked to picture a ladder with 10 steps and to tick next to the number that best described where they stood at that moment. The top of the 
ladder, 10 was the best possible family environment and at the bottom, 0 was the worst possible.

Perceived family wealth is an indicator that combines the perception of family absolute and relative economic wealth, measured by asking 'How well-off do you think your family is?'. The response range was from: 1) 'not at all well-off '; 2) 'not so well-off'; 3) 'average'; 4) 'quite well-off; 5) 'very well-off' (Griebler, Molcho, \& Samdal, 2010).

\section{Statistical analyses}

Data were analyzed firstly using descriptive statistics (mean and standard deviation) and correlations. To analyze the effects of parental unemployment, satisfaction with family environment and perceived family wealth in predicting change in youth life satisfaction, simple moderation and moderated moderation models of regression were performed using Hayes' PROCESS macro for SPSS (Hayes, 2013). Significance was determined at 95\% biascorrected confidence intervals and each analysis utilized a bootstrapping approach. To avoid multicollinearity issues all variables were centred prior to analysis, and the estimated effects reported are unstandardized regression coefficients (Hayes, 2013). Youth gender and age were controlled for in all models.

\section{Results}

The sample consisted of 2748 Portuguese students, with a mean age of 14.7 years ( $\mathrm{SD} \pm 1.2$ ). Approximately, $48 \%$ were boys and $19 \%$ reported to be living with one or both parents who were currently unemployed and looking for a job.

Table 1 presents descriptive statistics and correlations for the main variables. Life satisfaction was positively correlated with family life satisfaction, and negatively correlated with subjective family wealth. 
Table 1 Means, standard deviations, and correlations of key variables, ${ }^{*} p<.01$

\begin{tabular}{|c|c|c|c|c|}
\hline & Mean (SD) & 1 & 2 & 3 \\
\hline 1. Life satisfaction & $8.80(1.80)$ & - & & \\
\hline 2. Family life satisfaction & $7.44(1.96)$ & $.45^{*}$ & - & \\
\hline 3. Perceived family wealth & $3.26(0.70)$ & $.25^{*}$ & $.17^{*}$ & - \\
\hline
\end{tabular}

A simple moderation analysis using the PROCESS macro was performed to test the hypothesis that the link between parental unemployment and change in life satisfaction would be moderated by family life satisfaction (see Figure 1).

Fig. 1 Conceptual diagram of the moderation analysis: Effect of parental unemployment on youth life satisfaction moderated by family life satisfaction.

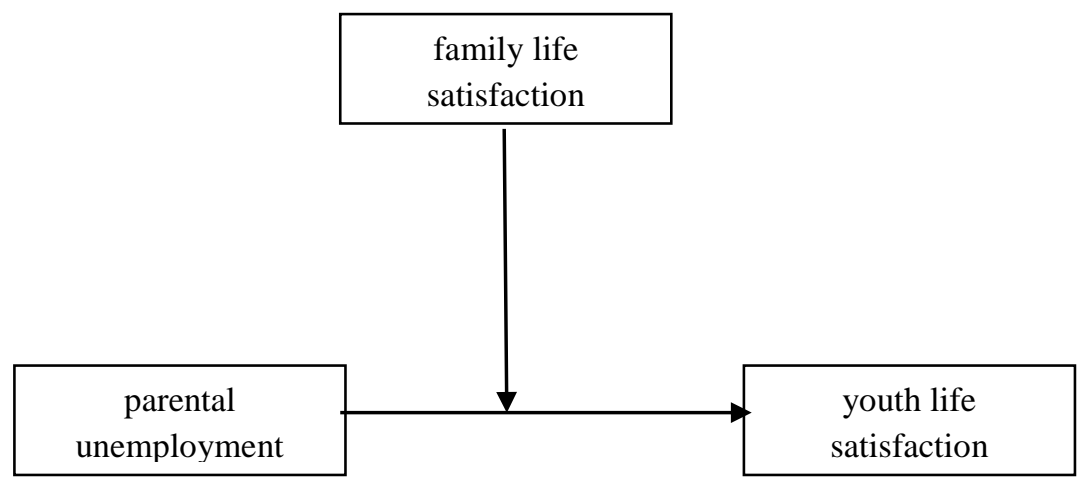

Parental unemployment and family life satisfaction accounted for a significant amount of variance in youth life satisfaction, $\mathrm{R}^{2}=.22, F(5,3662)=210.73, p<.001$. The interaction between these two variables (Fig.2) accounted for a statistically significant proportion of the variance in youth life satisfaction, $\left(\Delta \mathrm{R}^{2}=.0013, p=.013\right)$. Examination of the conditional effect values showed that good family life satisfaction has a moderation effect on the negative effect of parental unemployment on youth life satisfaction. 
Fig.2 Simple moderation analysis results with unstandardized regressions coefficients.

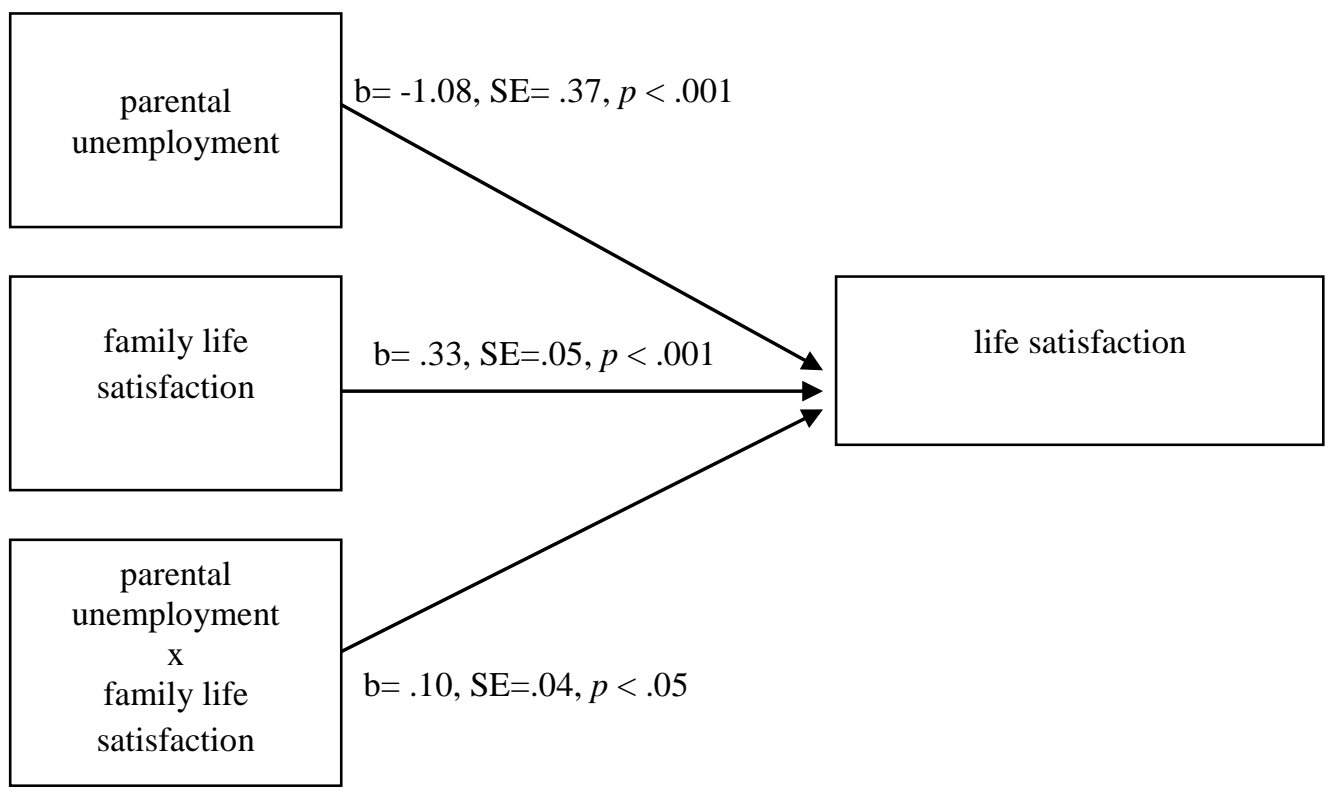

\section{Moderated moderation}

To test whether the interaction found between parental unemployment and family life satisfaction was moderated by perceived family wealth, a moderated moderation analysis (also known as three-way interaction) was performed (Fig 3).

Fig. 3 Conceptual diagram of the moderated moderation analysis: Effect of parental unemployment on change in youth life satisfaction as a function of family life satisfaction moderated by perceived family wealth

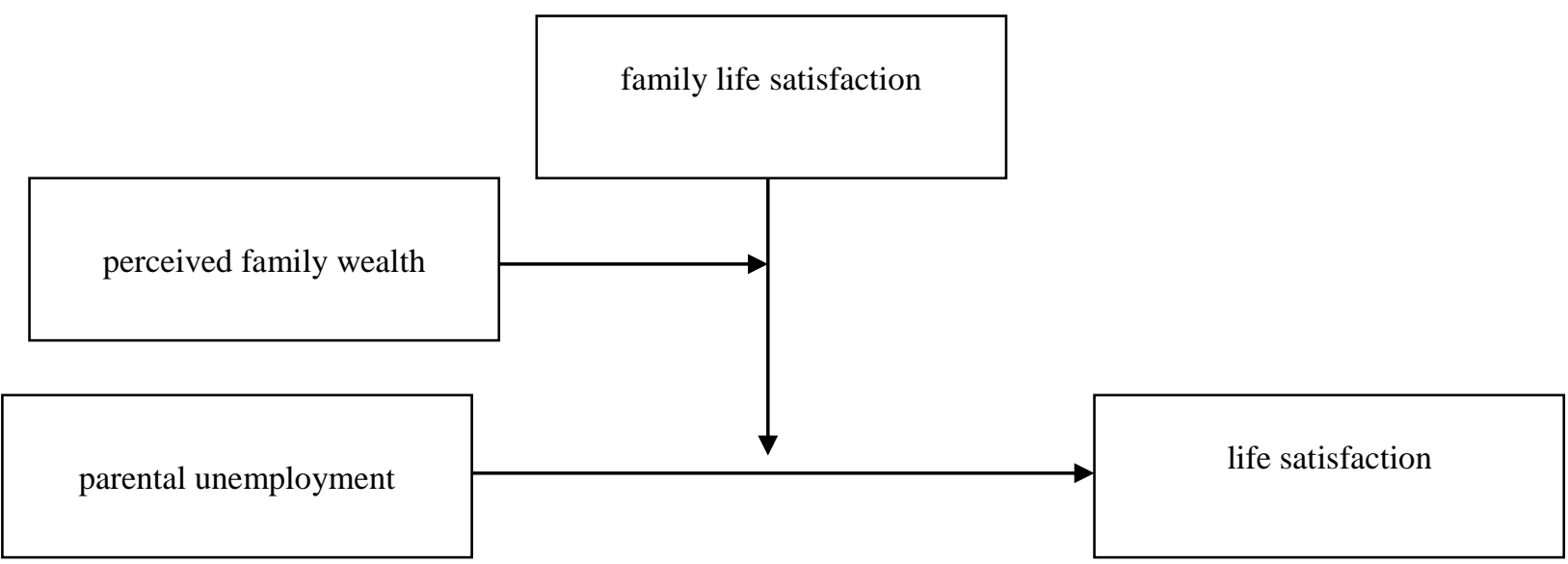

Altogether the model accounted for a significant amount of variance in youth life satisfaction, $\mathrm{R}^{2}=.26, F(9,3658)=141.12, p<.001$. Family life satisfaction and perceived family wealth were mean centered prior to the analysis by the PROCESS macro. The interaction between parental unemployment and family life satisfaction accounted for a 
significant moderation effect on life satisfaction $(b=.43, t(3658)=2.27, p<.05)$ but perceived family wealth did not significantly affect the strength of this relationship (Fig. 4). Examination of the conditional effect values showed that family life satisfaction buffered the negative effects of parental unemployment on youth's life satisfaction independently of perceived wealth.

Fig. 4 Moderated moderation analysis results with unstandardized regressions coefficients.

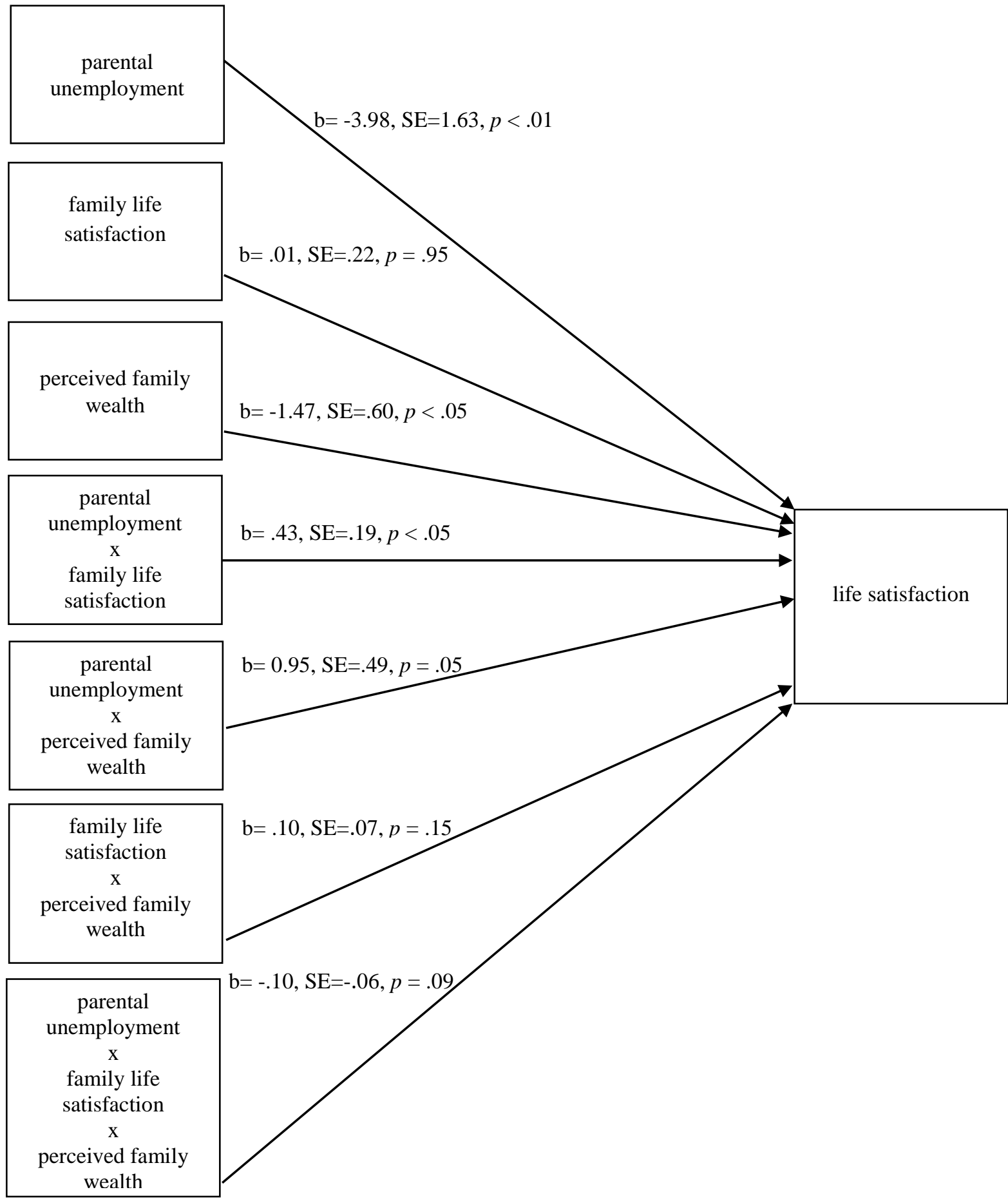




\section{Discussion}

In this study we examined the effect of parental unemployment on youth life satisfaction and the moderating roles of family life satisfaction and perceived family wealth. The results confirmed the hypothesis that parental unemployment is associated with youth low life statifaction, and that satisfaction with family life moderates this relationship. This means that the link between parental unemployment and youth low life satisfaction weakens when family life is perceived as being positive, and corroborates the idea that good family environment may act as a protector of the effects of parental unemployment on youth wellbeing (Maria Bacikova-Sleskova et al., 2011; Cui \& Conger, 2008; Willemen et al., 2011). Further, the moderated moderation analysis revealed that the association between parental unemployment and youth low life satisfaction was not moderated by combining family life satisfaction with perceived family economic position. This means that the moderation role of satisfaction with family life on the association between parental unemployment and youth's low life satisfaction was independent of the perceived wealth of the family. The results give some support to the family stress model (Rand D. Conger \& Elder Jr, 1994) by showing that parental unemployment is associated with youth low well-being, and that this association is moderated by the quality of the family life. Moreover, perceived family economic position did not influence this moderation link, suggeting that the association between parental unemployment and youth well-being goes beyond the financial situation of the family. The provides support for other studies which have also found that the association between parental unemployment and young people's well-being is unrelated to family economic situation (M. Bacikova-Sleskova, Benka, \& Orosova, 2015; Frasquilho et al., 2015; Powdthavee \& Vernoit, 2013; Reinhardt Pedersen, Madsen, \& Kohler, 2005).

Nonetheless, these findings should be interpreted with caution since causal inference and generalization are limited to the cross-sectional design of this study. Moreover, it is 
important to consider that the analysis was performed with self-reported data, which has the advantage of measuring youth's perception of family wealth but can differ from 'reality' (e.g. young people may not want to reveal socially undesirable family economic positions) and this could have modified the effect of perceived family wealth in the model. However, the variable used to assess family well-off in this study has been shown to reflect dimensions of family socioeconomic position while relating to health and health behaviour outcomes in the HBSC study (Griebler et al., 2010). It is also important to note that although the moderating role of family life satisfaction on the relationship between parental unemployment and youth life satisfaction was significant, the variance accounted for by this moderation was relatively low. We believe this is because unemployment in the family is a complex phenomenon and many variables that we could not account for may also operate in the moderation model (e.g. duration of the unemployment and level of parental stress). Despite the low value, its statistical significance indicates an association which warrants further research.

This study contributes to a deeper understanding of the effect of parental unemployment in youth life satisfaction in school-aged children, and is the first to our knowledge to use a nationwide population-sample. The moderating role of youth satisfaction with family life on the effect of parental unemployment on life satisfaction highlights the importance of accounting for the family context in jobless homes. In particular, the results point to the importance of quality of family life - rather than solely the financial consequences - on youth well-being during unemployment in the family. Future research is needed to provide evidence for causality of the effects (e.g. longitudinal design studies) and raise awareness of the associations between parental unemployment and changes in youth well-being. Moreover, this body of research might help improve policy-making by suggesting that jobless families not only need financial assistance, but may also require aditional resources to maintain and improve family life satisfaction during periods of labour market 
crisis and economic recession (e.g. making parenting support programmes available for families facing unemployment). Supporting jobless families may help interrupt the deleterious intergenerational consequences of unemployment for well-being, thereby maximising the health opportunities of young people in unemployed families.

\section{Conclusion}

This study examined whether parental unemployment is associated with youth low life satisfaction, and whether this association is moderated by satisfaction with family life and by family economic position. Results showed that parental unemployment was associated with lower youth life satisfaction scores, and that satisfaction with family life moderated this relationship. The findings suggest a transmission of the negative consequences of parental unemployment on young people's well-being, and that good family environment exerts a significant moderation effect on this association. These findings contribute to the existing literature delineating the impact of parental unemployment upon young people, which is particularly important given the labour market and unemployment crises currently facing many families. 


\section{Key findings}

- parental unemployment is associated with low youth life satisfaction scores;

- young people satisfied with their family life are less vulnerable to the negative effects of parental unemployment on their life satisfaction;

- This moderation role is independent of perceived family wealth;

- the findings improve our knowledge about possible associations between parental unemployment and youth well-being during the economic downturn and labour market crisis, by taking into account the possible buffer-effect of maintaining or promoting positive family life;

- parental unemployment seems to entail important social consequences that affect the family context (rather than solely financial), these may be addressed when researching and supporting jobless families and their children. 


\section{References}

Bacikova-Sleskova, M., Benka, J., \& Orosova, O. (2015). Parental employment status and adolescents' health: The role of financial situation, parent-adolescent relationship and adolescents' resilience. Psychol Health, 30(4), 400-422. doi:10.1080/08870446.2014.976645

Bacikova-Sleskova, M., Madarasova Geckova, A., van Dijk, J. P., Groothoff, J. W., \& Reijneveld, S. A. (2011). Parental support and adolescents' health in the context of parental employment status. Journal of Adolescence, 34(1), 141-149. doi:http://dx.doi.org/10.1016/j.adolescence.2010.01.003

Baxter, J., Gray, M., Hand, K., \& Hayes, A. (2012). Parental joblessness, financial disadvantage and the wellbeing of parents and children. Retrieved from

Broman, C. L., Hamilton, V. L., \& Hoffman, W. S. (1997). The impact of unemployment on families. Michigan Family Review, 2(2).

Cantril, H. (1965). The pattern of human concerns. New Brunswick, NJ: Rutgers University Press.

Christoffersen, M. N. (2000). Growing Up with Unemployment: A Study of Parental Unemployment and Children's Risk of Abuse and Neglect Based on National Longitudinal 1973 Birth Cohorts in Denmark. Childhood, 7(4), 421-438.

Conger, R. D., \& Conger, K. J. (1992). A family process model of economic hardship and adjustment of early adolescent boys. Child Development, 63(3), 526. doi:10.1111/14678624.ep9207061028

Conger, R. D., \& Donnellan, M. B. (2007). An interactionist perspective on the socioeconomic context of human development. Annu Rev Psychol, 58, 175-199. doi:10.1146/annurev.psych.58.110405.085551

Conger, R. D., \& Elder Jr, G. H. (1994). Families in Troubled Times: Adapting to Change in Rural America. Social Institutions and Social Change: ERIC.

Cui, M., \& Conger, R. D. (2008). Parenting Behavior as Mediator and Moderator of the Association Between Marital Problems and Adolescent Maladjustment. Journal of Research on Adolescence, 18(2), 261-284. doi:10.1111/j.1532-7795.2008.00560.x

Currie, C., Nic Gabhainn, S., Godeau, E., Roberts, C., Smith, R., \& Currie, D. (2008). Inequalities in young people's health: Health behaviour in school-aged children international report from the 2005/06 survey. Retrieved from Copenhagen:

Currie, R. L. (2009). Using collaborative action research to identify and support young people at risk of becoming NEET. Educational \& Child Psychology, 26(1), 67-75.

Diener, E., Suh, E., Lucas, R. E., \& Smith, H. L. (1999). Subjective well-being: Three decades of progress. Psychological Bulletin, 125(2), 276-302.

Eurostat. Jobless households - children. Retrieved from: http://ec.europa.eu/eurostat/tgm/table.do?tab=table\&init=1\&language=en\&pcode=tps001 81\&plugin=1

Fanjul, G. (2014). Children of the Recession: The impact of the economic crisis on child well-being in rich countries. Retrieved from

Frasquilho, D., de Matos, M., Marques, A., Neville, F., Gaspar, T., \& Caldas-de-Almeida, J. M. (2015). Unemployment, Parental Distress and Youth Emotional Well-Being: The Moderation Roles of Parent-Youth Relationship and Financial Deprivation. Child Psychiatry \& Human Development, 1-8. doi:10.1007/s10578-015-0610-7

Griebler, R., Molcho, M., \& Samdal, O. (2010). Health Behaviour in School-Aged Children: World Health Organization Cross-National Study. Research Protocol for the 2009/2010 Survey Retrieved from Edinburgh: 
Hayes, A. F. (2013). Introduction to mediation, moderation, and conditional process analysis: A regression-based approach: Guilford Press.

Kuntsche, E. N., \& Gmel, G. (2004). Emotional wellbeing and violence among social and solitary risky single occasion drinkers in adolescence. Addiction, 99(3), 331-339.

Leinonen, J. A., Solantaus, T. S., \& Punamäki, R.-L. (2002). The specific mediating paths between economic hardship and the quality of parenting. International Journal of Behavioral Development, 26(5), 423-435.

McClelland, A. (2000). Effects of Unemployment on the Family. The Economic and Labour Relations Review, 11(2), 198-212.

Molcho, M., Gabhainn, S. N., Kelly, C., Friel, S., \& Kelleher, C. (2007). Food poverty and health among schoolchildren in Ireland: findings from the Health Behaviour in School-aged Children (HBSC) study. Public health nutrition, 10(04), 364-370.

Muldoon, J., Levin, K., van der Sluijs, W., \& Currie, C. (2010). Validating mental well-being items of the Scottish health behaviour in school-aged children (HBSC) survey. Edinburgh: University of Edinburgh.

Paul, K. I., \& Moser, K. (2009). Unemployment impairs mental health: Meta-analyses. Journal of Vocational Behavior, 74(3), 264-282. doi:http://dx.doi.org/10.1016/i.jvb.2009.01.001

Powdthavee, N., \& Vernoit, J. (2013). Parental unemployment and children's happiness: A longitudinal study of young people's well-being in unemployed households. Labour Economics, 24(0), 253-263. doi:http://dx.doi.org/10.1016/j.labeco.2013.09.008

Reinhardt Pedersen, C., Madsen, M., \& Kohler, L. (2005). Does financial strain explain the association between children's morbidity and parental non-employment? J Epidemiol Community Health, 59(4), 316-321. doi:10.1136/jech.2003.013839

Reising, M., Watson, K., Hardcastle, E., Merchant, M., Roberts, L., Forehand, R., \& Compas, B. (2013). Parental Depression and Economic Disadvantage: The Role of Parenting in Associations with Internalizing and Externalizing Symptoms in Children and Adolescents. Journal of Child and Family Studies, 22(3), 335-343. doi:10.1007/s10826-012-9582-4

Siponen, S., Ahonen, R., Savolainen, P., \& Hameen-Anttila, K. (2011). Children's health and parental socioeconomic factors: a population-based survey in Finland. BMC Public Health, 11(1), 457.

Sleskova, M., Salonna, F., Geckova, A. M., Nagyova, I., Stewart, R. E., van Dijk, J. P., \& Groothoff, J. W. (2006). Does parental unemployment affect adolescents' health? J Adolesc Health, 38(5), 527-535. doi:10.1016/j.jadohealth.2005.03.021

Varga, S., Piko, B. F., \& Fitzpatrick, K. M. (2014). Socioeconomic inequalities in mental well-being among Hungarian adolescents: a cross-sectional study. Int J Equity Health, 13(1), 100. doi:10.1186/s12939-014-0100-8

Viner, R. M., Ozer, E. M., Denny, S., Marmot, M., Resnick, M., Fatusi, A., \& Currie, C. (2012). Adolescence and the social determinants of health. Lancet, 379(9826), 1641-1652. doi:10.1016/S0140-6736(12)60149-4

Wall, K., Almeida, A. d., Vieira, M., Cunha, V., Rodrigues, L., Coelho, F., .. A Atalaia, S. (2013). As Crianças e a Crise em Portugal: Vozes de Crianças, Políticas Públicas e Indicadores Sociais 2013. Retrieved from Lisboa:

Willemen, A. M., Schuengel, C., \& Koot, H. M. (2011). Observed Interactions Indicate Protective Effects of Relationships With Parents for Referred Adolescents. Journal of Research on Adolescence, 21(3), 569-575. doi:10.1111/j.1532-7795.2010.00703.x 